\title{
VARIASI PARITAS ANITA PASANGAN USIA SUBUR (PUS) UMUR 45-49 TAHUN DI KECAMATAN MENGWI KABUPATEN BADUNG BALI
}

\author{
Oleh: \\ Ni Komang Sinta Ratnasari, Dr. Ida Bagus Made Astawa, M.Si. , I Made Sarmita, S.Pd, M.Sc \\ Jurusan Pendidikan Geografi, Fakultas Hukum dan Ilmu Sosial, Undiksha \\ Email: sintaratna34@gmail.com, idabagusmadeastawa@yahoo.com, \\ made.sarmita@undiksha.ac.id
}

\begin{abstract}
ABSTRAK
Penelitian ini dilaksanakan di Kecamatan Mengwi Kabupaten Badung Bali dengan tujuan: (1) menganalisis variasi paritas Wanita PUS umur 45-49 tahun di Kecamatan Mengwi, dan (2) menganalisis faktor-faktor yang mempengaruhi paritas wanita PU umur 45-49 tahun di Kecamatan Mengwi. Penelitian ini dirancang sebagai penelitian deskriptif dengan sampel areal pada tiga desa/kelurahan yang ditentukan secara purposif dan subjek sampel sebesar 10\% (82 PUS Wanita Usia 45 - 49 Tahun) dari populasi sebesar 815 yang ditentukan secara proporsional random sampling. Pengumpulan data primer menggunakan metode wawancara, dan data sekunder menggunakan metode pencatatan dokumen.Data diolah dan selanjutnya dianalisis secara deskriptif kuanlitatif. Hasil penelitian menunjukan bahwa (1) Terdapat variasi Paritas Wanita Umur 45-49 Tahun antar desa/kelurahan di Kecamatan Mengwi. (2) faktor-faktor yang merpengaruhi variasi paritas wanita PUS Umur 45-49 Tahun di Kecamatan Mengwi adalah faktor sosial (pendidikan), pekerjaan, dan budaya. Faktor ekonomi (pendapatan) tidak berpengaruh terhadap paritas PUS Wanita Umur 45 - 49 Tahun di Kecamatan Mengwi.
\end{abstract}

Kata Kunci: Paritas, Pasangan Usia Subur, Wanita Usia 45 - 49 Tahun, Faktor Pendidikan, Faktor Pekerjaan, Faktor ekonomi, Faktor Budaya

\begin{abstract}
The research was conducted in Mengwi Subdistrict, Badung Regency, Bali with the objectives of: (1) analyzing the variations in parity of PUS women aged 45-49 years in Mengwi Subdistrict, and (2) analyzing the factors that affect parity of PU women aged 45-49 years in Mengwi District . This study was designed as a descriptive study with a sample area in three villages / villages that were purposively determined and the sample subject was 10\% (82 PUS for Women Aged 45 - 49 Years) from a population of 815 determined proportionally random sampling. Primary data collection uses interview method, and secondary data uses document recording method. Data is processed and subsequently analyzed descriptively. The results showed that (1) There were variations in the Parity of Women aged 45-49 years between villages / kelurahan in Mengwi District. (2) the factors that influence the variation in parity of PUS women aged 45-49 years in Mengwi Subdistrict are social (education), work, and cultural factors. Economic factors (income) have no effect on PUS parity for women aged 45 - 49 years in Mengwi sub-district.
\end{abstract}


Keywords: Parity, Fertile Age Couples, Women Age 45 - 49 Years, Educational Factors, Job Factors, Economic Factors, Cultural Factors

\section{PENDAHULUAN}

Provinsi Bali dengan luas 5.636,66 kilometer persegi atau 0,29 persen dari luas wilayah daratan seluruh Indonesia memiliki jumlah penduduk yang senantiasa meningkat dari waktu ke waktu. Dilihat dari hasil sensus penduduk (SP) tahun 1961 tercapai jumlah penduduk Provinsi Bali sebesar 1.782 .529 orang. Jumlah penduduk Provinsi Bali setiap tahun mengalami peningkatan dari tahun 1971 sampai tahun 2010 yang mencapai jumlah 3.890.757 orang. Laju pertumbuhan penduduk Provinsi Bali menunjukkan penurunan selama Masa Orde Baru, dan sebaliknya meningkat selama Masa Reformasi. Pada awal Masa Orde Baru, laju pertumbuhan penduduk Provinsi Bali adalah 1,75 persen per tahun selama periode 1961-1971, kemudian turun menjadi 1,71 persen per tahun pada periode 1971-1980, dan turun lagi menjadi 1,18 persen per tahun pada periode 1980- 1990. Pada Masa Reformasi, justru terjadi hal yang sebaliknya, laju pertumbuhan penduduk meningkat dengan pesat, yaitu dari 1,26 per tahun pada periode 19902000 menjadi 2,14 persen per tahun pada periode 2000-2010 (BPS Provinsi Bali, 2016).

Laju pertumbuhan penduduk Provinsi Bali yang mencapai 2,14 persen per tahun pada periode 2000- 2010, menunjukkan angka yang jauh lebih tinggi daripada angka nasional yang besarnya 1.49 persen per tahun pada periode yang sama. Salah satu komponen demografi yang dipandang berpengaruh besar terhadap laju pertumbuhan penduduk tersebut adalah kecendrungan meningkatnya jumlah migran risen yang masuk ke Bali. Namun di sisi lain juga terjadi pertumbuhan peningkatan angka fertilitas penduduk yang ditunjukan oleh peningkatan TFR Provinsi Bali dari 1,89\% menjadi 2,14\% kelahiran hidup per wanita usia reproduksi selama periode 2000-2010, dan penurunan usia kawin pertama wanita dari 23,1 tahun (SP 2000) menjadi 22,4 tahun (SP 2000). Peningkatan ini diperkuat dari hasil Survei Demografi dan Kesehatan Indonesia (SDKI) 2012 yang menyebutkan besarnya TFR Provinsi Bali adalah sebesar 2,3 kelahiran hidup per wanita (Sudibia, 2013). Hal ini menunjukan bahwa fertilitas juga berperan dalam meningkatkan laju pertumbuhan penduduk di Provinsi Bali. Jadi dengan demikian, dinamika penduduk yang terjadi di Provinsi Bali tidak lepas dari variable-veriabel demografi, seperti fertilitas, mortalitas, dan migrasi.

Istilah fertilitias sering disebut dengan kelahiran hidup (live birth), yaitu 'terlepasnya 
bayi dari rahim seorang wanita dengan adanya tanda-tanda kehidupan” seperti bernapas, berteriak, bergerak, jantung berdenyut, dan lain sebagainya. Sementara paritas merupakan jumlah anak yang telah dimiliki oleh seorang wanita. Apabila waktu lahir tidak ada tanda-tanda kehidupan maka disebut dengan lahir mati (still live) yang di dalam demografi tidak dianggap sebagai suatu peristiwa kelahiran (Pollard, 1989 dalam Astawa, 2018: 132). Keberhasilan Program Keluarga Berencana di Bali mencapai 68\% lebih yang melampaui presentase nasional yang hanya 59\%. Program peserta Keluarga Berencana di Bali tergolong berhasil, terbukti dari 100 orang pasangan usia subur, 68 hingga 70 pasangan sudah menjadi peserta KB. Sementara peserta KB baru terhadap target di Kabupaten Badung mencapai 124.10\% dari jumlah KB bar 9.661 dari target yang direncanakan mencapai 7.785 dengan ini pencapaian target peserta KB telah melampaui presentase yang telah ditentukan.

Kepala BKKBN Provinsi Bali mengatakan bahwa di tahun 2017 Provinsi Bali Total Fertility Rate (TFR) atau tingkat rata-rata kelahiran anak setiap wanita selama masa subur juga tergolong kecil yakni 2,21 anak sedangkan rata-rata nasional jumlah anak 2,4 anak. Berdasarkan data sensus penduduk tahun 2010 laju pertumbuhan penduduk di Provinsi Bali mencapai 2,15\% lebih tinggi dari presentase nasional 1,49\%. Namun tingginya laju pertumbuhan penduduk di Provinsi Bali bukan disebabkan tingginya kelahiran tetapi akibat pesatnya migrasi terutama di Kabupaten Badung, Denpasar, dan Gianyar (RRI, 2018). Meningkatnya jumlah penduduk Bali yang cukup besar tersebut perlu dikaji lebih jauh, karena Kepala perwakilan BKKBN Provinsi Bali, I Wayan Sundra menargetkan, sasaran akseptor KB baru di Bali adalah sebanyak 64.640 orang dan 555.010 pasangan peserta KB aktif dalam tahun 2013. Sementara sasaran yang diharapkan pengguna Metode Kontrasepsi Jangka Panjang (MKJP) adalah sebesar 26.732 orang yang diharapkan menunjang keberhasilan KB di Bali. Selain itu, ada kemungkinan peningkatan laju pertumbuhan Bali dipengaruhi oleh model KB Bali yang isu akhir-akhir ini, yaitu dengan empat anak. KB dengan empat anak diyakini budaya untuk sebutan anak dengan wayan (anak pertama), made (anak kedua), nyoman (anak ketiga), dan ketut (anak keempat) tidak menjadi hilang. Model KB dengan empat anak ini juga dikemukakan dilatar belakangi oleh kesadaran masyarakat Bali dengan ke-Hinduan-nya.

Peningkatan pertumbuhan yang terjadi, yang jelas dapat disebabkan oleh dua hal, yaitu peningkatan angka kelahiran sementara angka kematian menurun dan adanya arus migran masuk yang lebih tinggi dari migran ke luar. Peningkatan angka kelahiran berkorelasi dengan 
keberhasilan program KB yang diimplementasikan pemerintah provinsi Bali dengan berbagai permasalahan yang dialami memasuki era reformasi. Berkenaan dengan permasalahan program KB di Bali dan Model KB Bali yang berkembang akhir-akhir ini tentu akan berdampak secara luas. PUS yang secara otomatis sebagai orang tua dituntut untuk dapat menghidupi anak-anak dan segala kebutuhannya secara layak. Hal ini yang perlu disadari, sehingga dalam hal ini perlu adanya perubahan cara pandang tentang KB Bali. Masyarakat Bali dengan tingkat kemampuan ekonomi yang bervariasi dalam memenuhi kebutuhannya sudah tentu harus merencanakan secara rasional jumlah anak yang harus dimiliki.

Dilihat dari kondisi Demografi Kabupaten Badung jumlah penduduk yang setiap tahun meningkat, peningkatan penduduknya termasuk rendah. Selama kurun waktu Desember tahun 2015 sampai Desember 2016, pertumbuhan penduduk Kabupaten Badung kurang dari 2\% yaitu mencapai 1,06 \%. Hal ini disebabkan kerena adanya penghapusan data kependudukan yang terdeteksi ganda baik dalam maupun antara kabupaten berdasarkan data perekaman KTP-el dan kriteria ganda antara elemen biodata penduduk. Selain faktor migran masuk, faktor utama yang dinilai mempengaruhi peningkatan tersebut adalah tingkat kelahiran. Dan dilihat dari kondisi Demografi Kecamatan Mengwi jumlah penduduk setiap tahunnya mengalami peningkatan dari tahun 2012 sampai 2016 peningkatan jumlah penduduk mencapai 1.2\%. Perilaku fertilitas pada era reformasi tentu tidak dipengaruhi oleh paritas paripurna yang telah dicapai penduduk wanita pernah kawin yang sudah mencapai usia 45 - 49 tahun. Namun demikian, sampai saat ini perilaku fertilitas wanita pernah kawin yang telah mencapai usia 45 - 49 tahun belum pernah dikaji, termasuk yang terjadi di Kecamatan Mengwi yang menjadi sentral pemerintahan di Kabupaten Badung dengan jumlah penduduk yang selalu mengalami peningkatan.

Berdasarkan latar belakang yang telah dikemukakan diatas maka adapun rumusan maslah sebagai berikut: (1) Bagaimana variasi paritas wanita PUS umur 45-49 tahun di Kecamatan Mengwi? (2) factor-faktor apakah yang mempengaruhi paritas wanita PUS umur 4549 tahun di Kecamatan Mengwi?

\section{METODE PENELITIAN}

Rancangan penelitian ini memberikan arahan tentang sampel penelitian, pengumpulan data dan teknik analisis data (Sriartha, 2004). Rancangan penelitian yang digunakan dalam penelitian ini adalah deskriptif. Menurut Sukmadinata (2011) penelitian deskriptif ditunjukan 
untuk mendeskrisikan atau menggambarkan fenomena-fenomena yang ada, baik fenomena yang bersifat alamiah atau rekayasa manusia, secara deskriptif pengumpulan data dan informasi untuk memberikan gambaran atau penegasan suatu konsep atau gejaladan menjawab pertanyaanpertanyaan. Penelitian ini mendeskripsikan tentang (1) paritas wanita umur 45-49 tahun, dan (2) faktor-faktor yang mempengaruhi paritas penduduk wanita PUS usia 45-49 tahun. Penelitian ini juga menggunakan penelitian kuantitatif yang merupakan suatu metode untuk menguji teori-teori dengan cara meneliti hubungan antara variabel. Sehingga penelitian kuantitatif untuk menganalisis hubungan pengetahuan KB dengan jumlah paritas di Kecamatan Mengwi antara 3 desa (Kapal, Gulingan, Munggu). Daerah yang dijadikan sebagai lokasi penelitian adalah di Kecamatan Mengwi Kabupaten Badung Bali dengan mencangkup 3 wilayah desa yaitu desa Kapal, desa Gulingan dan desa Munggu.

Populasi wilayah dalam penelitian ini adalah desa di Kecamatan Mengwi maka diperoleh data tentang jumlah penduduk sebesar 3721 PUS umur 45-49 tahun yang tersebar di 20 desa/keluarahan di Kecamatan Mengwi. Penentuan sampel area ditentukan secara Purposive. Yaitu desa Kapal, desa Gulingan dan desa Munggu di Kecamatan Mengwi. observasi awal 3 desa tersebut memiliki jumlah paritas tertinggi, sedang dan rendah. Desa tersebut dalam spetifikasi wilayah kota, pinggir kota dan desa. Tujuannya untuk melihat jumlah paritas wanita PUS umur 45-49 tahun disetiap wilayah.

Penentuan subjek mengacu pada ketentuan yang dikemukakan Arikunto (2011), sebagai ancar-ancar apabila subjeknya kurang dari 100 orang lebih baik keseluruhan populasi digunakan sebagai sampel, sehingga disebut penelitian populasi. Selanjutnya jika subjeknya lebih besar dari 100 dapat diambil $5-10 \%$ atau $15-20 \%$ atau lebih tergantung dari peneliti, dilihat dari homogenitas dan luas wilayah pengamatan dari setiap subjek. Mengingat jumlah populasi lebih dari 100, maka sampel yang digunakan sebanyak $10 \%$ dari populasi yaitu sebanyak 815 responden.

\section{HASIL DAN PEMBAHASAN}

\section{Variasi Paritas Wanita PUS Umur 45-49 Tahun di Kecamatan Mengwi}

Paritas sebagai akumulasi dari fertilitas yang dimiliki wanita semasa hidupnya cenderung bervariasi antar wilayah. Dari hasil penelitian ini di Kecamatan Mengwi diantara 3 desa yaitu desa Kapal, Gulingan dan Munggu menunjukan bahwa adanya variasi paritas wanita PUS umur 
45-49 tahun. Status wilayah antara 3 desa mempengaruhui jumlah paritas yang dimiliki. Didesa Kapal merupakan daearah kota dengan jumlah paritas yang lebih tinggi dibandingan dengan desa Gulingan dengan status wilayah pinggiran kota dan desa Munggu dengan status wilayah desa memiliki jumlah paritas yang lebih rendah. Ini disebabkan adanya perbedaan yang berkaitan dengan fasilitas maupun karakteristik sosial, ekonomi, dan budaya yang dimiliki disetiap wilayah tersebut. Namun demikian, fenomena pada tiga desa/kelurahan di Kecamatan Mengwi ini menunjukkan keberhasilan Program KB pada masa itu yang ditunjukkan oleh rata-rata anak yang dimiliki PUS Wanita Usia 45 - 49 tahun berkisar anatar 2 - 3 anak. Peningkatan fertilitas akhirakhir ini di Kecamatan Mengwi bukan dikontribusi oleh wanita PUS umur 45-49 tahun saja melainkan disumbangkan oleh generasi berikutnya.

Berdasarkan hasil temuan dalam penelitian ini dan didukung oleh temuan dari didukung temuan dari peneliti lain maka dapat dikemukakan bahwa terdapat variasi paritas Wanita PUS Usia 45 - 49 Tahun antar desa di Kecamatan Mengwi. Variasi paritas Wanita PUS Usia 45 - 49 Tahun antar desa di kecamatan Mengwi tidak dapat dikaitkan dengan status kewilayahan yang disandang oleh desa bersangkutan saat ini secara keruangan (Kapal tergolong Kota, Gulingan tergolong Pinggiran Kota, dan Munggu tergolong Desa), karena kelahiran yang terjadi sudah berlangsung 20 samapai 10 tahun yang lalu pada saat masih menyandang status sama-sam tergolong desa.

\section{Faktor-faktor Yang Mempengaruhi Paritas Wanita PUS Umur 45-49 tahun di Kecamatan Mengwi \\ Paritas sebagai akumulasi dari fertilitas wanita semasa hidupnya dapat dipengaruhi faktor-faktor seperti pendidikan, pekerjaan, ekonomi, dan budaya. Berikut merupakan pembahasan mengenai faktor-faktor yang mempengaruhi paritas yang dimaksud.}

\section{1) Faktor Sosial (Pendidikan)}

Pendidikan pada umumnya berpengaruh pada paritas, karena semakin tinggi pendidikan ada kemungkinan UK 1 semakin tinggi pula sehingg masa memanfaatkan waktu reproduksinya semakin pendek. Perhatikan Tabel 01. 
Tabel 01. Rata-rata Paritas Wanita PUS Usia 45 - 49 Tahun pada Tiga Desa di Kecamatan Mengwi menurut Tingkat Pendidikan

\begin{tabular}{|c|c|c|c|c|c|c|c|c|c|}
\hline \multirow{3}{*}{ No. } & \multirow{3}{*}{ Pendidikan } & \multicolumn{6}{|c|}{$\begin{array}{c}\text { Rata-Rata Paritas Wanita PUS } \\
\text { Usia } 45 \text { - } 49 \text { Tahun di Desa/Kelurahan }\end{array}$} & \multicolumn{2}{|c|}{ Total } \\
\hline & & \multicolumn{2}{|c|}{ Kapal } & \multicolumn{2}{|c|}{ Gulingan } & \multicolumn{2}{|c|}{ Munggu } & \multirow[b]{2}{*}{ RataRata } & \multirow[b]{2}{*}{$\mathbf{N}$} \\
\hline & & $\begin{array}{l}\text { Rata } \\
\text { Rata }\end{array}$ & $\mathbf{N}$ & $\begin{array}{l}\text { Rata } \\
\text { Rata }\end{array}$ & $\mathbf{N}$ & $\begin{array}{l}\text { Rata } \\
\text { Rata }\end{array}$ & $\mathbf{N}$ & & \\
\hline (1) & (2) & (3) & (4) & (5) & (6) & (7) & (8) & (9) & (10) \\
\hline 1 & Tidak Tamat SD & 0 & 0 & 0 & 0 & 0 & 0 & 0 & 0 \\
\hline 2 & Tamat SD & 0 & 0 & 0 & 0 & 0 & 0 & 0 & 0 \\
\hline 3 & Tamat SMP & 2,6 & 17 & 2,9 & 12 & 2,7 & 7 & 2,75 & 36 \\
\hline 4 & Tamat SMA & 2,4 & 13 & 2,1 & 13 & 2 & 10 & 2,22 & 36 \\
\hline 5 & Tamat PT & 2,2 & 4 & 1,7 & 4 & 2 & 2 & 2 & 10 \\
\hline \multicolumn{2}{|c|}{ Rata-Rata Paritas Total } & 2,47 & 34 & 2,13 & 29 & 2,05 & 19 & 2,25 & 82 \\
\hline
\end{tabular}

Sumber: Pengolahan Data Primer, 2018

Tabel 01 menunjukan bahwa Faktor sosial yang dalam hal ini adalah pendidikan berkorelasi negatif terhadap paritas. Semakin tinggi pendidikan, semakin sedikit jumlah anak yang dimiliki. Pendidikan yang dimaksud dalam penelitian ini sebagai faktor yang mempengaruhi paritas adalah pendidikan terakhir yang ditamatkan Wanita PUS Usia 45 -49 Tahun di kecamatan Mengwi. . Hasil penelitian menunjukkan bahwa pendidikan terakhir yang ditamatkan Wanita PUS Usia 45 - 49 Tahun di kecamatan Mengwi tergolong sedang. Tidak terdapat wanita PUS Usia 45 - 49 Tahun yang hanya berpendidikan SD atau Tidak Pernah Sekolah. Pendidikan terendahnya adalah SMP (dominan) dan tertingginya adalah Perguruan Tinggi. Semakin tinggi pendidikan seorang wanita PUS maka semakin rendahnya tingkat paritas yang terjadi. Kerena dengan memiliki pendidikan yang tinggi seorang wanita PUS akan dapat berpikir menerima dan merencanakan jumlah anak yang diingin didalam keluarga. Dengan adaya program pemerintah dengan menentukan jumlah "dua anak cukup sama saja" ini bisa dijalan didalam keluarganya. 


\section{2) Faktor Pekerjaan}

Pekerjaan-pekerjaan yang sangat terikat dengan waktu (sektor formal) cenderung akan menyebabkan seorang wanita membatasi jumlah anak yanga akan dilahirkan. Di kecamatan Mengwi, paritas PUS Wanita Usia 45 - 49 Tahun dilihat dari pekerjaannya dapat dilihat pada table berikut.

Tabel 02. Rata-rata Paritas Wanita PUS USia 45 - 49 Tahun pada Tiga Desa di Kecamatan Mengwi menurut Faktor Pekerjaan

\begin{tabular}{|c|c|c|c|c|c|c|c|c|c|}
\hline \multirow{3}{*}{ No. } & \multirow{3}{*}{ Jenis Pekerjaan } & \multicolumn{6}{|c|}{$\begin{array}{c}\text { Rata-Rata Paritas Wanita PUS } \\
\text { Usia } 45 \text { - } 49 \text { Tahun di Desa/Kelurahan }\end{array}$} & \multicolumn{2}{|c|}{ Total } \\
\hline & & \multicolumn{2}{|c|}{ Kapal } & \multicolumn{2}{|c|}{ Gulingan } & \multicolumn{2}{|c|}{ Munggu } & \multirow[b]{2}{*}{ RataRata } & \multirow[b]{2}{*}{$\mathbf{N}$} \\
\hline & & $\begin{array}{l}\text { Rata } \\
\text { Rata }\end{array}$ & $\mathbf{N}$ & $\begin{array}{l}\text { Rata } \\
\text { Rata }\end{array}$ & $\mathbf{N}$ & $\begin{array}{l}\text { Rata } \\
\text { Rata }\end{array}$ & $\mathbf{N}$ & & \\
\hline (1) & (2) & (3) & (4) & (5) & (6) & (7) & (8) & (9) & (10) \\
\hline 1 & Pertanian & 0,29 & 4 & 1,31 & 15 & 0,94 & 7 & 0,80 & 26 \\
\hline 2 & Peternakan & 0,05 & 1 & 0,48 & 7 & 0 & 0 & 0,19 & 8 \\
\hline 3 & Perdagangan & 1,35 & 18 & 0,37 & 4 & 0,57 & 5 & 0,82 & 27 \\
\hline 4 & Bank & 0,08 & 1 & 0 & 0 & 0,10 & 1 & 0,06 & 2 \\
\hline 5 & Pemerintahan & 0,73 & 10 & 0,03 & 1 & 0,21 & 2 & 0,36 & 13 \\
\hline 6 & Kontruksi & 0 & 0 & 0,17 & 2 & 0,15 & 2 & 0,09 & 4 \\
\hline 7 & Industri & 0 & 0 & 0 & 0 & 0,21 & 2 & 0,04 & 2 \\
\hline \multicolumn{2}{|c|}{ Rata-Rata Paritas Total } & 2,47 & 34 & 2,13 & 29 & 2,05 & 19 & 2,25 & 82 \\
\hline
\end{tabular}

Sumber: Pengolahan Data Primer, 2018

Pekerjaan yang dimiliki seorang wanita menjadikannya lebih merencanakan jumlah anak yang akan dimiliki dan kapan harus memiliki anak. Beberapa instansi bahkan mempersyaratkan pekerjanya tidak menikah pada awal-awal bekerja. Hal ini berpengaruh terhadap jumlah paritas yang dimiliki sehingga untuk merencanakan menikah pada usia muda harus ditunda karena faktor pekerjaan yang dimiliki seorang wanita. Namun pekerjaan yang tidak mengikat secara formal, seperti dibidang pertanian, perdagangan, dan yang sejenisnya tidak menuntut persyaratan tidak menikah tersebut. Hal tersebut sudah tentu akan berpengaruh terhadap paritas yang 
dimiliki. Dalam penelitian ini dari 7 jenis pekerjaan yang teridentifikasi yang ditekeni oleh wanita PUS di Kecamatan Mengwi, paritas yang tinggi dimiliki oleh mereka yang bekerja sebagai petani dan pedagang. Pekerjaan di luar pertanian dan perdagangan yang dapat menyita waktu seorang wanita, menunjukkan paritas yanga lebih rendah.

\section{3) Faktor Ekonomi}

Faktor ekonomi yang dalam hal ini adalah pendapatan dapat berpengaruh terhadap paritas PUS Wanita Usia 45 - 49 Tahun. Untuk jelasnya dari hasil penelitian yang dilakukan di kecamatan Mengwi, perhatikan Tabel 03.

Tabel 03. Rata-rata Paritas Wanita PUS Usia 45 - 49 Tahun pada Tiga Desa di Kecamatan Mengwi menurut Pendapatan

\begin{tabular}{|c|c|c|c|c|c|c|c|c|c|}
\hline \multirow{3}{*}{ No. } & \multirow{3}{*}{$\begin{array}{l}\text { Pendapatan (Dalam } \\
\text { Juta Rupiah) }\end{array}$} & \multicolumn{6}{|c|}{$\begin{array}{l}\text { Rata-Rata Paritas Wanita PUS } \\
\text { Usia } 45 \text { - } 49 \text { Tahun di Desa/Kelurahan }\end{array}$} & \multicolumn{2}{|l|}{ Total } \\
\hline & & \multicolumn{2}{|c|}{ Kapal } & \multicolumn{2}{|c|}{ Gulingan } & \multicolumn{2}{|c|}{ Munggu } & \multirow[b]{2}{*}{ Rata-Rata } & \multirow[b]{2}{*}{$\mathbf{N}$} \\
\hline & & $\begin{array}{l}\text { Rata } \\
\text { Rata }\end{array}$ & $\mathbf{N}$ & $\begin{array}{l}\text { Rata } \\
\text { Rata }\end{array}$ & $\mathbf{N}$ & $\begin{array}{l}\text { Rata } \\
\text { Rata }\end{array}$ & $\mathbf{N}$ & & \\
\hline (1) & (2) & (3) & (4) & (5) & (6) & (7) & (8) & (9) & (10) \\
\hline 1 & $1,0-1,4$ & 4,3 & 3 & 2,7 & 4 & 3 & 2 & 3,3 & 9 \\
\hline 2 & $1,5-1,9$ & 2,5 & 4 & 2 & 3 & 2 & 2 & 2,2 & 9 \\
\hline 3 & $2,0-2,4$ & 2,3 & 13 & 2 & 8 & 2,5 & 7 & 2,3 & 28 \\
\hline 4 & $2,5-2,9$ & 2,3 & 8 & 2,8 & 9 & 2,2 & 4 & 2,5 & 21 \\
\hline 5 & $>2,9$ & 2,5 & 6 & 2,2 & 5 & 1,7 & 4 & 2,2 & 15 \\
\hline \multicolumn{2}{|c|}{ Rata-Rata Paritas Total } & 2,47 & 34 & 2,13 & 29 & 2,05 & 19 & 2,25 & 82 \\
\hline
\end{tabular}

Sumber: Pengolahan Data Primer, 2018

Tabel 03 menunjukkan bahwa pendapatan Wanita PUS Usia 45 - 49 Tahun di kecamatan Mengwi dikategorikan sedang (Rp. 2.000.000 - Rp. 2.500.000). PUS Wanita Usia 45-49 Tahun di Kecamatan Mengwi yang tergolong berpendapat tinggi, keadaan paritasnya tergolong tinggi karena dengan memiliki pendapat yang tinggi memungkinkan untuk memfasilitasi semua 
kebutuhan anaknya yang diinginkan. Namun mereka yang berpendapatan rendah juga ternyata memiliki paritas yang lebih tinggi. Hal ini menunjukkan bahwa pendapatan tidak berpengaruh terhadap paritas. Namun variasi antar desa terjadi di kecamatan Mengwi. Linieritas pola paritas berdasarkan pendapatan di kecamatan Mengwi tidak terlihat secara jelas.

\section{4) Faktor Budaya}

Faktor budaya sangat berkaitan dengan fertilitas. Budaya yang mengharuskan memiliki anak laki-laki cenderung menyebabkan jumlah anak yang dimiliki oleh seorang wanita menjadi tinggi. Pengaruh factor budaya terhadap paritas PUS Wanita Usia 45 - 49 Tahun di kecamatan Mengwi dapat dilihat pada Tabel 04.

Tabel 04. Rata-rata Paritas Wanita PUS USia 45 - 49 Tahun pada Tiga Desa di Kecamatan Mengwi menurut Faktor Budaya

\begin{tabular}{|c|c|c|c|c|c|c|c|c|c|}
\hline \multirow{3}{*}{ No. } & \multirow{3}{*}{$\begin{array}{c}\text { Pernyataan } \\
\text { Persetujuan } \\
\text { terhadap Budaya* }\end{array}$} & \multicolumn{6}{|c|}{$\begin{array}{c}\text { Rata-Rata Paritas Wanita PUS } \\
\text { Usia } 45 \text { - } 49 \text { Tahun di Desa/Kelurahan }\end{array}$} & \multicolumn{2}{|l|}{ Total } \\
\hline & & \multicolumn{2}{|c|}{ Kapal } & \multicolumn{2}{|c|}{ Gulingan } & \multicolumn{2}{|c|}{ Munggu } & \multirow[b]{2}{*}{ Rata-Rata } & \multirow[b]{2}{*}{$\mathbf{N}$} \\
\hline & & $\begin{array}{l}\text { Rata } \\
\text { Rata }\end{array}$ & $\mathbf{N}$ & $\begin{array}{l}\text { Rata } \\
\text { Rata }\end{array}$ & $\mathbf{N}$ & $\begin{array}{l}\text { Rata } \\
\text { Rata }\end{array}$ & $\mathbf{N}$ & & \\
\hline (1) & (2) & (3) & (4) & (5) & (6) & (7) & (8) & (9) & (10) \\
\hline 1 & $\mathrm{Ya}$ & 2,5 & 7 & 2,9 & 10 & 2,6 & 8 & 2,72 & 25 \\
\hline 2 & Tidak & 2,3 & 27 & 2,1 & 19 & 1,9 & 11 & 2,24 & 57 \\
\hline \multicolumn{2}{|c|}{ Rata-Rata Paritas Total } & 2,47 & 34 & 2,13 & 29 & 2,25 & 19 & 2,25 & 82 \\
\hline
\end{tabular}

Sumber: Data primer 2018

* Pentingnya anak laki-laki dalam suatu keluarga.

Faktor budaya yang dimaksudkan dalam hal ini adalah pandangan Wanita PUS Usia 45 49 Tahun terhadap memiliki anak laki-laki dalam sebuah keluarga. Budaya patriliniat menyebabkan pentingnya anak laki-laki dalam sebuah keluarga. Budaya Bali pada umumnya juga menjadikan anak laki-laki penting ada dalam sebuah keluarga, karena berkaitan dengan meneruskan keturunan sebagai pewaris yang berkewajiban untuk mengelola (memperbaiki, 
mengupacarai, dan sebaginya) tempat sembahyang keluarga (Pemerajan/Sanggah/Kawitan, dan sebagainya) dan kewajiban-kewajiban adat di Desa Pekramannya, jadi bukan hanya pewarisan materi. Hasil penelitian menunjukkan bahwa sebagian besar Wanita PUS Usia 45 - 49 Tahun di Kecamatan Mengwi memiliki pandangan pentingnya anak laki-laki dalam suatu keluarga. Faktor Budaya dengan memiliki anak laki-laki dalam satu keluarga dianggap sangat penting, kerena anak laki-laki ini dijadikan dalam penerus keluarga. Hasil temuan dalam penelitian ini menunujukan bahwa pasangan usia subur (PUS) yang menyatakan "pentingnya" anak laki-laki dalam keluarga memiliki paritas yang lebih tinggi dibandingkan yang menyatakan tidak. Hal ini membuktikan bahwa jika belum adanya anak laki-laki dalam satu keluarga maka PUS akan merencanakan memiliki anak laki-laki sehingga paritasnya menjadi lebih tinggi.

\section{PENUTUP}

Berdasarkan hasil pembahasan yang dilakukan dapat disimpulkan bahwa terdapat variasi paritas wanita PUS usia 45-49 tahun pada tiga desa (Kapal, Gulingan dan Munggu) di Kecamatan Mengwi. Desa Kapal dominan pada paritas 3 anak, sementara dua desa lainnya dominan dengan 2 anak. Sementara faktor-faktor yang berpengaruh terhadap paritas wanita (PUS) di Kecamatan Mengwi adalah sosial (pendidikan), pekerjaan, dan budaya. Sedangkan factor pendapatan tidak berpengaruh terhadap paritas PUS Wanita Usia 45 - 49 Tahun.

Mengacu pada pembahasan dan simpulan yang telah dikemukakan maka dapat diajukan beberapa saran sebagai berikut. 1) Peningkatan fertilitas di kecamatan Mengwi akhir-akhir ini bukan disumbangkan oleh Wanita PUS Usia 45 - 49 Tahun. Berkenaan dengan itu, sangat dibutuhkan peningkatan pemahaman PUS usia muda di kecamatan Mengwi terhadap pentingnya pengendalian kependudukan dilakukan melalui Gerakan Keluarga Berencana. 2) Pendidikan kependudukan yang memfokuskan pada pengendalian kelahiran juga dinilai urgen diberikan kepada generasi muda di kecamatan Mengwi, sehingga pada saat menjadi PUS dapat merencanakan kapan melahirkan dan berapa jumlah anak yang diinginkan sesuai dengan kemampuan keluarga bersangkutan. 3) Perlu dilakukan penelitian yang lebih luas lagi dengan menggunakan sampel yang besar untuk melihat bagaimana variasi paritas di daerah lain, sehingga dapat dijadikan bahan komparasi bagi penelitian yang telah dilakukan ini. 
Daftar Pustaka

Aditya, N. (2010). KB Bali Sasaran Pembelajaran Tujuan Negara. Retrieved Juli 2017, from Bali.antaranews: bali.antaranews.com/berita/44101/kb-bali-sasaran-pembelajaran-tujuannegara

Anggapurana. (n.d.). Reformasi Keluarga Berencana Bali 4 Anak Sudah Cukup. balidewatapost.blogsport.co.id/2014/02/reformasi-keluarga-berencana-bali-4.html.

Antara, A. P. (2012). Hasil Program KB di Balli Positif Meski Penduduk Meningkat . Beritasatu, www.beritasatu.com/kesehatan/36082-hasil-program-kb-di-bali-positid-meski-pendudukmeningkat.html.

Ari, W. (2015). digilib.unimus. Retrieved from jptunimus: http://digilib.unimus.ac.id/download.php?id=9753

Arif. (2016, januari). ArifPedia. Retrieved april 11, 2017, from ArifPedia: http://ariefpedia.blogspot.co.id/2015/07/pengertian-geografi-penduduk.html

Arikunto. (2013). Prosedur Penelitian: Suatu Pendekatan Praktik. Jakarta: Rineka Cipta. Arikunto. (2013). Prosedur Penelitian: Suatu Pendekatan Praktik. Jakarta: Rineka Cipta.

Astawa Ida Bagus Made. (2015). kajian geografi. Migran di kota Negara dan Faktor-faktor yang mempengaruhi, 1-5.

Astawa Ida Bagus Made, Sarmita I Made. (2018). Geografi Penduduk. Depok: PT RAJAGRAFINDO PERSADA.

Astawa Ida Bagus Made, I. G. (n.d.). Migran di kota Negara dan faktor-faktor yang mempengaruhinya (Kajian Geografi Penduduk). Kajian Geografi, 1-11.

Bappenas. (2009). Keluarga Berencana. Keluarga Berencana, 3-4.

BKKBN. (n.d.). BKKBN pentingnya program KB di Indonesia. Retrieved Agustus 2017, from BKKBN: https://tirto.id/bkkbn-ingatkan-pentingnya-program-kb-di-peringatan-harganascsLW

BPS Kabupaten Badung. (2011). Profil Potensi Desa di Kabupaten Badung Tahun 2011. In B. K. Badung, Profil Potensi Desa di Kabupaten Badung Tahun 2011 (pp. 13-14). Badung, Bali: BPS Kabupaten Badung.

BPS. (2015). Kecamatan Mengwi Dalam Angka 2015. Kabupaten Badung Bali: Badan Pusat Statistika.

BPS. (2015). Kecamatan Mengwi Dalam Angka 2015. In BPS, BPS (pp. 11-12). Badung, Bali.

BPS. (2016). Profil Perkembangan Kependudukan Kabupaten Badung Tahun 2016. Kabupaten

BAdung Bali: Dinas Kependudukan Dan Pencatatan Sipil tahun 2017.

BPS, Kabupaten Badung. (2017). Statistika Demografi dan sosial Ekonomu Rumah Tangga

Provinsi Bali. In BPS, Statistika Demografi dan sosial Ekonomu Rumah Tangga Provinsi Bali (pp. 5-7). Bali: https://bali.bps.go.id/publication.html.

BPS, Kabupaten Badung. (2013). BPS Kecamatan Mengwi Dalam Angka 2013. Badung Bali: BPS Kabupaten Badung.

Budiman Elheat, R. K. (2017). Hubungan Tingkat Pendidikan, Pekerjaan, Status Ekonomi, Dengan Paritas Di Puskesmas Bahu Manado . e-journal Keperawatan (e-Kp) VOL 5 NO 1. Februari 2017, 1-2. 
Chayang, Y. Y. (2014). Hubungan Persepsi Nilai Anak dengan Jumlah dan Jenis Kelamin Anak yang Diinginkan pada Wanita Usia Subur Pranikah di Pedesaan. Departemen Biostatiska dan Kependudukan, 1-2.

Depkes. (1999). Jurnal Bidan Diah. Retrieved from Jurnal Bidan Diah : jurnalbidandiah.blogspot.co.id/2012/07/program-kb-di-indonesia.html

Depkes. (2010). keluarga berencana. Retrieved maret 12, 2017

Diah, B. (2012). Program KB di Indonesia. Program KB di Indonesia, 2-3.

DISCAPIL, Kabupaten Badung. (2016). Profil Perkembangan Kependudukan Kabupaten Badung 2016. Badung, Bali: 2017.

Farahansuah, N. (2016). Gambaran Tingkat Pengetahuan Penggunaan Alat Kontasepsi Pada Wanita Usia Subur Dan Dukungan Petugas Di DEsa Bebandem Kabupaten Karangasem Bali Tahun 2014. e-jurnal medika, vol.5 No.4, April 2016, 1-2.

Fitia, V. L. (2015). Paritas Dengan Usia Menopause Di Desa Kembang Ringgit Kecamatan Pungging Kabupaten Mojokerto. Laporan Penelitian Paritas , 1-2.

Health, World. (2013, januari). World Health. Retrieved Juni 12, 2017, from World Health Web site: http://worldhealth-bokepzz.blogspot.co.id/2012/05/faktor-yang-mempengaruhiparitas.html

Hermawan, S. (2016, juli 13). KB Bali: 1 Anak Berkualita atau 4 Anak Tak karuan. KB Bali: 1 Anak Berkualita atau 4 Anak Tak karuan, 1-2.

Kanali. (2016). Kanalinfo. Retrieved Agustus 2017, from Kanalinfo.web.id: http://www.kanalinfo.web.id/2016/10/pengertian-data-primer-dan-data-sekunder.html

Lilik Indahwati, L. R. (2017, agustus). karakteristika Ibu ( usia, paritas, pendidikan, pengalaman kb) berhubungan dengan pemilihan metode kontasepsi. Retrieved juli 26, 2018, from journal of issues in midwifery: http://joim.ub.ac.id/index.php.joim/article/view/31

Mahagangga, o. (2015). seminar nasional sain dan teknologi (senastek), denpasar bali 2015. kajian pengembangan desa wisata di kabupaten badung, 5-6.

Mantra Ida bagus. Prof, P. (1990). Demografi Umum. Bali.

Nalasari, P. (2014). Pengaruh Faktor Sosial, Ekonomi, dan Demografi Terhadap Jumlah Anak Yang Dilahirkan Hidup Di Kecamatan Pesantren Kota Kendari. Jurnal Mahasiswa Unesa, 1-2.

Nyoman, R. N. (2015). Perempuan Bali dalam Pergulatan Gender (Kajian Budaya, Tradisi, dan Agama Hindu). Jurnal Studi Kuturan, 1-2.

Nyoman, S. (n.d.). Faktor-faktor pendorong terjadinya hegemoni terhadap perempuan dalam pelaksanaan program keluarga berencana(studi kasus di kecamatan Tejakula, Buleleng Bali). studi kasus dikecamatan Tejakula, Buleleng Bali. 